\title{
Osmotic dehydration kinetics of fresh and frozen blueberries considering volume shrinkage in a novel ternary solution
}

\author{
Da-Heng YANG ${ }^{1,2 *}$ (D), Xiao-Yan $\mathrm{LI}^{2}$, Yi-Fan $\mathrm{ZHAO}^{2}$, Qing-Min $\mathrm{HOU}^{2}$, Qing-Yao MENG ${ }^{2}$,i LI ${ }^{2}$
}

\begin{abstract}
Osmotic dehydration is a nonthermal processing technology, that is limited in blueberries because of the osmotic agent, temperature and efficiency. This study was to prepare a novel ternary solution considering low-sugar, low-salt and low-viscosity requirements and to dehydrate blueberries at $20^{\circ} \mathrm{C}$. The mass transfer kinetics of fresh and frozen blueberries were explored in ternary solution considering the volume shrinkage of blueberries. The results showed that the $40 \% / 50 \%$ xylitol solution had the lowest viscosity in polyols at $20^{\circ} \mathrm{C}$. The addition of $5 \% / 10 \% \mathrm{CaCl}_{2}$ had no significant effect on the viscosity of the ternary solution. Frozen blueberries had higher OD efficiency and less equilibrium time than fresh blueberries at $600 \mathrm{rpm}$ vibration speed and $50 \% x y l i t o l / 10 \% \mathrm{CaCl}_{2}$ concentration. There was competition between xylitol and $\mathrm{CaCl}_{2}$ transfer at shorter dehydration times for fresh blueberries, which was not significant in frozen blueberries and with longer times. Considering volume shrinkage of the blueberries, the effective diffusion coefficient of water and solute was calculated. The vibration speed had a significant effect on the effective diffusion coefficient, which governed the mass transfer efficiencies of the blueberries in the ternary solution.
\end{abstract}

Keywords: blueberries; osmotic dehydration; xylitol; calcium chloride; effective diffusion coefficient.

Practical Application: A low-sugar, low-salt and low-viscosity ternary solution is explored to dehydrate fresh and frozen blueberries at $20^{\circ} \mathrm{C}$. Mass transfer kinetics are explored for fresh and frozen blueberries in this ternary solution at $20^{\circ} \mathrm{C}$. More accurate effective diffusion coefficients for water, xylitol and $\mathrm{CaCl}_{2}$ are calculated considering the volume shrinkage of the blueberries. The effects of vibration speed and solute concentration on the effective diffusion coefficients of water and xylitol are clarified.

\section{Introduction}

Osmotic dehydration (OD) is a nonthermal technology for preserving and processing fruit (Junqueira et al., 2021; Dermesonlouoglou \& Giannakourou, 2018; Kowalska et al., 2017). This method can extend the shelf life of blueberries and produce intermediate-moisture products with better stability (GrajalesLagunes et al., 2019; Yu et al., 2016). The further development of OD in blueberries is hindered by osmotic agents and efficiency (Yu et al., 2016; Ciurzyńska et al., 2016; Kucner et al., 2013; Ketata et al., 2013). Sucrose is one of the most commonly used osmotic agents in the OD of blueberries (Yadav \& Singh, 2014; Vega-Gálvez et al., 2012). However, the use of sucrose to dehydrate fruits will increase the sugar content and the calorific value of the final products, which are important because glycemic index and calorific intake are dietary concerns among consumers, particularly those who are diabetics (Shi et al., 2017). In recent studies, many researchers have tried a variety of low sugar solutions, including polyols and low-sugar fruit juice, to reduce the calorie content and glycemic index of dehydrated products (Cichowska et al., 2018; Akharume et al., 2016). The high viscosities of sucrose, polyols and low-sugar fruit juice solution limits their applications in the OD of blueberries at low temperature $\left(<25^{\circ} \mathrm{C}\right)$, and many physicals methods, such as vibration and stirring, cannot improve the efficiency (Dimakopoulou-Papazoglou \& Katsanidis, 2019;
Telis et al., 2004; Tonon et al., 2007). Higher temperature can improve the OD efficiency, but high temperature is harmful to the anthocyanins and phenols in blueberries (Allan-Wojtas et al., 2001; $\mathrm{Yu} Y$ et al., 2017). Anthocyanins are antioxidants and important solutes in a healthier product (Grajales-Lagunes et al., 2019). To improve the efficiency of OD for blueberries, the use of a ternary solution can increase the osmotic pressure gradient of the solution without reaching the saturation limit of the OD solute (Dimakopoulou-Papazoglou \& Katsanidis, 2019; Telis et al., 2004; Derossi et al., 2015). Sodium chloride ( $\mathrm{NaCl})$ is a common OD solute in ternary solutions (Telis et al., 2004; Tonon et al., 2007; Derossi et al., 2015). However, excessive intake of sodium in the human-body can cause high blood pressure and cardiovascular disease (Rodrigues et al., 2016; Silva et al., 2014). In studies of the OD of fruits and vegetables, calcium chloride $\left(\mathrm{CaCl}_{2}\right)$ is a new salt substitute (Silva et al., 2014; Jesus Junqueira et al., 2017). Compared with $\mathrm{NaCl}, \mathrm{CaCl}_{2}$ has lower effects on the physio-chemical and sensory properties of dehydrated products and can also avoid the negative effects of $\mathrm{NaCl}$ (Jesus Junqueira et al., 2017). In addition, the skin of blueberries is a determinant factor that hinders mass transfer during the OD process (Kucner et al., 2013; Ketata et al., 2013). Freezing treatment is a low-cost and ordinary processing technology 
for perishable blueberries, and is also helpful for improving the moisture impermeability of blueberry skin (Ketata et al., 2013).

At present, studies on the OD of blueberries are mostly carried out in binary sucrose solutions and at high temperatures $\left(50^{\circ} \mathrm{C}\right.$, $60^{\circ} \mathrm{C}$ ) (Ketata et al., 2013), and there are sparse scientific data on the OD of blueberries in low-sugar, low-salt and low-viscosity solutions at lower temperatures. The application of a low-viscosity polyols $/ \mathrm{CaCl}_{2}$ ternary solution in the OD of blueberries has not been reported. In a low-temperature environment, mechanical stirring and vibration can be used to strengthen the OD diffusion process and improve the OD efficiency. The mass transfer and economic benefit can be enhanced with the improved efficiency (Junqueira et al., 2021). It is not clear whether the mass transfer is predominantly governed by a diffusion mechanism or by the external resistance of the solution under the different skin conditions of fresh and frozen blueberries. The effective diffusion coefficient and dehydration equilibrium time are not clear in the $\mathrm{OD}$ of blueberries in polyols $/ \mathrm{CaCl}_{2}$ ternary solution. Furthermore, the effective diffusion coefficients of water and solute during OD are mostly based on Fick's second law without considering the volume shrinkage of fruit (Ketata et al., 2013; Song et al., 2020; Nsonzi \& Ramaswamy, 1998). However, an accurate value of diffusion coefficients should be used by taking into account volume shrinkage under different OD processing conditions (Junqueira et al., 2017).

This study aimed to create a low-sugar, low-salt and lowviscosity OD solution and to investigate the effects of the ternary solution on the OD kinetics of the fresh and frozen blueberries at the temperature of $20^{\circ} \mathrm{C}$ by (1) preparing the ternary OD solution(polyols/ $\mathrm{CaCl}_{2} /$ water) according to the viscosity and temperature of the solution (2) determining the equilibrium times and volume shrinkage levels of fresh and frozen blueberries in this ternary OD solution (3) modeling the mass transfer processes of water and solute to determine the effective diffusion coefficient while considering volume shrinkage; and (4) investigating the effects of vibration speed and solution concentration on the OD kinetics of blueberries.

\section{Materials and Methods}

\subsection{Blueberries and osmotic dehydration treatment}

Fresh blueberries (V. corymbosum L.) were purchased from the local fruit wholesale market and were stored in the refrigerator at $4^{\circ} \mathrm{C}$. After individual quick freezing treatment $\left(-80^{\circ} \mathrm{C}\right)$, frozen blueberries were stored at $-18^{\circ} \mathrm{C}$ in a freezer. Prior to the experiment, frozen blueberries were thawed at room temperature $\left(20^{\circ} \mathrm{C}\right)$ for $2 \mathrm{~h}$ and were blotted dry to remove surface water.

Polyols, sucrose and $\mathrm{CaCl}_{2}$ (analytical reagent grade) were purchased from the local chemicals market and distilled water was used to prepare the solutions. The viscosities of the solutions were determined by Thermo fisher HAAKE (Viscotester 550, Thermo fisher Scientific, Inc., IA, USA). In the OD experiment, $20 \mathrm{~g}$ of blueberries was immersed in an Erlenmeyer flask (with a rubber stopper) containing $200 \mathrm{~mL}$ of xylitol/ $\mathrm{CaCl}_{2}$ solution, with a 1:10 ratio of blueberries to solution. In OD processes, the processing time is usually lower than the time required to reach the complete equilibrium of the product with the solution (Monnerat et al., 2010). To reach OD equilibrium, the fresh and frozen blueberries were subjected to OD processing for $30 \mathrm{~h}$. Sampling was performed at $1 \mathrm{~h}$ intervals of $0-10 \mathrm{~h}$ and at $2 \mathrm{~h}$ intervals of 10-30 h. In the experiments, the blueberries were removed from the solution, rinsed quickly with water, blotted dry to remove surface water, and then weighed to determine the water content, xylitol gain and $\mathrm{CaCl}_{2}$ gain of the blueberries. In the process of OD, mechanical stirring and vibration of the solution could decrease the external resistance of the boundary layer of diffusion (Dimakopoulou-Papazoglou \& Katsanidis, 2016). Thermostatic vibration equipment $(600 \mathrm{rpm})$, a thermostatic water bath and an air conditioning system were used to reinforce the OD process of fresh and frozen blueberries at a controlled temperature $\left(20^{\circ} \mathrm{C}\right)$, because mechanical stirring destroyed the blueberries in the preliminary experiment.

\subsection{Kinetics research on the OD of blueberries in ternary solution}

In this research, the analytical solution of Fick's second law was used to determine the effective diffusion coefficients of water, xylitol and $\mathrm{CaCl}_{2}$ for blueberries in ternary solutions. To calculate effective diffusion coefficient of the blueberries, water ratio and solid ratio ( $W R$ and $S R$ ) were calculated by normalizing the water (solute) content of the time $t$ interval with the initial water content and modeled by analytical solution of Fick's second law (Equations 1-3).

$$
\begin{aligned}
& W R=\frac{M_{t} c_{t}-M_{e} c_{e}}{M_{0} c_{0}-M_{e} c_{e}}=\frac{8}{\pi^{2}} \sum_{n=0}^{\infty} \frac{1}{(2 n+1)^{2}} \exp \left(\frac{-3600 D_{\text {water }}(2 n+1)^{2} \pi^{2} t}{r^{2}}\right) \\
& S R^{\text {xylitol }}=\frac{M_{e} s_{e}-M_{t} s_{t}}{M_{e} s_{e}-M_{0} s_{0}}=1-\frac{8}{\pi^{2}} \sum_{n=0}^{\infty} \frac{1}{(2 n+1)^{2}} \exp \\
& \left(\frac{-3600 D_{x y l i t o l}(2 n+1)^{2} \pi^{2} t}{r^{2}}\right)
\end{aligned}
$$

$$
S R^{\mathrm{CaCl} / 2}=\frac{M_{e} s_{e}-M_{t} s_{t}}{M_{e} s_{e}-M_{0} s_{0}}=1-\frac{8}{\pi^{2}} \sum_{n=0}^{\infty} \frac{1}{(2 n+1)^{2}} \exp
$$$$
\left(\frac{-3600 D_{C a C l 2}(2 n+1)^{2} \pi^{2} t}{r^{2}}\right)
$$

where: $c_{\mathrm{t}}$ is the water content of blueberries in OD at time $t$ (\%); $c_{\mathrm{e}}$ is the water content of blueberries in OD at equilibrium time (\%); $s_{\mathrm{t}}$ is the xylitol or $\mathrm{CaCl}_{2}$ gain of blueberries in $\mathrm{OD}$ at time $t(\%) ; s$ is the xylitol or $\mathrm{CaCl}_{2}$ gain of blueberries in $\mathrm{OD}$ at equilibrium time (\%); $M_{0}$ is the mass of blueberries at the initial time $(\mathrm{g}) ; M_{\mathrm{t}}$ is the mass of blueberries at time $t(\mathrm{~g}) ; M_{\mathrm{e}}$ is the mass of blueberries at equilibrium time $(\mathrm{g}) ; D_{\text {water }} D_{\text {xylitol }}$ and $D_{\mathrm{CaCl} 2}$ are the effective diffusion coefficient $\left(10^{-10} \mathrm{~m}^{2} / \mathrm{s}\right) ; r$ is the average radius of blueberries $(\mathrm{m})$; and $n$ is the calculation factor of diffusion coefficient nonlinear regression equation, $n=8$.

Without considering any volume shrinkage of the blueberries, $r$ is an average constant $(r=6.94 \mathrm{~mm}$ for fresh blueberries, $r=5.91 \mathrm{~mm}$ 
for frozen blueberries) which was measured with 50 samples. Taking into account volume shrinkage, the effective radius of blueberries was determined by Equation 4 (Omobuwajo et al., 1999). An electronic caliper was used to measure $a, b$ and $c$ before and after the freezing and OD treatment (Figure 1b). Taking into account the radius shrinkage, effective diffusion coefficients were calculated based on the adjusted radius.

$r_{e}=\frac{(a b c)^{1 / 3}}{2}$

where: $r$ is the effective radius of blueberries. $a$ is the maximum diameter $(\mathrm{mm}), b$ is the intermediate diameter $(\mathrm{mm})$ and $c$ is the minimum diameter $(\mathrm{mm})$ of the blueberries (Figure 1.(b)).

The water content of blueberries was determined by a weight measurement according to the AACC 83 method 44-15A. The xylitol content was determined by HPLC (Agilent 1100, Agilent Technologies, Inc., California, USA) (Chen et al., 2013). The $\mathrm{CaCl}_{2}$ content of blueberries was determined by the atomic absorption method (PerkinElmer AA700, PerkinElmer, Inc., Massachusetts, USA) and direct titration using $\mathrm{AgNO}_{3}$ (Renato D et al., 2017).

The nonlinear estimation program Prism version 6.01 (GraphPad Software Inc., San Diego, CA, USA) was used to calculate the effective diffusion coefficients of water, xylitol and $\mathrm{CaCl}_{2}$. The analysis of the significant differences in water content, xylitol and $\mathrm{CaCl}_{2}$ gain were performed by a $95 \%$ significance level analysis and a Tukey's test.

\subsection{Experimental design of solution concentration and vibration speed on the effective diffusion coefficient of blueberries}

The regression analysis of the effects of the diffusion coefficients for the fresh and frozen blueberries against different solution concentrations and vibration speeds was presented by a rotatable central composite design with a total of 17 experiments and three independent variables: $\mathrm{CaCl}_{2}$ concentration (5-10\%), xylitol concentration (40-50\%) and vibration speed (0-600 rpm). The response variable $Y\left(D_{\text {water }}, D_{\text {xylitol }}\right.$ and $\left.D_{\mathrm{CaCl} 2}\right)$ listed in Equation 5 was fitted to the data in terms of three independent process variables $\left(\mathrm{CaCl}_{2}\right.$ concentration, xylitol concentration and vibration speed).

$Y=\beta_{0}+\beta_{I} x_{I}+\beta_{2} x_{2}+\beta_{3} x_{3}+\beta_{11} x_{I}^{2}+\beta_{22} x_{2}^{2}+\beta_{33} x_{3}^{2}+$
$\beta_{12} x_{1} x_{2}+\beta_{13} x_{1} x_{3}+\beta_{23} x_{2} x_{3}$

where: $Y$ is the response variable $\left(D_{\text {water }}, D_{\text {xylitol }}\right.$ and $\left.D_{\mathrm{CaCl} 2}\right)$; $\beta_{n}$ is the equation regression coefficient; and $x_{n}$ is the coded independent variable $\left(\mathrm{CaCl}_{2}\right.$ concentration, xylitol concentration and vibration speed).

Analysis of variance (ANOVA), determination of the regression coefficients, testing for the lack of fit and the generation of three-dimensional graphs were performed using Design Expert (version 8.0.5, State-Ease Inc., Minneapolis, MN, USA).

\section{Results and discussion}

\subsection{Determination of the components and parameters of the ternary solution}

To compare the characteristics of polyols, xylitol, sorbitol, erythritol, mannitol and maltitol were assessed and measured for viscosity, molecular weight and solubility. To ensure sufficient osmotic pressure in the OD process, $40 \%$ and $50 \%$ mass concentration percentages of polyols and sucrose were selected. Solution crystallization phenomena were found for mannitol at both $10^{\circ} \mathrm{C}$ and $20^{\circ} \mathrm{C}$. The solubility of mannitol is $17 \mathrm{~g} / 100 \mathrm{gH}_{2} \mathrm{O}$ at $20^{\circ} \mathrm{C}$, which means that mannitol cannot be used to prepare ternary solutions at $40 \%$ concentration and

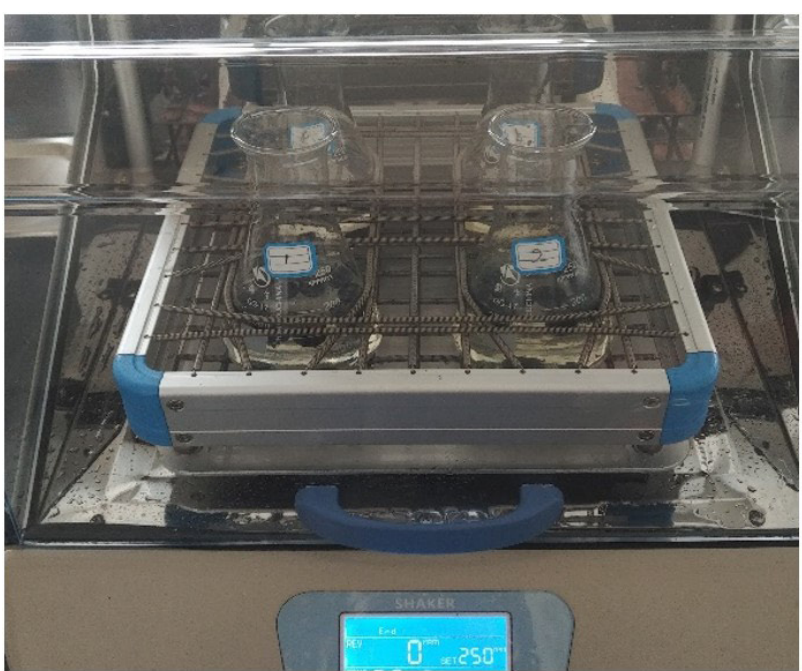

(a)

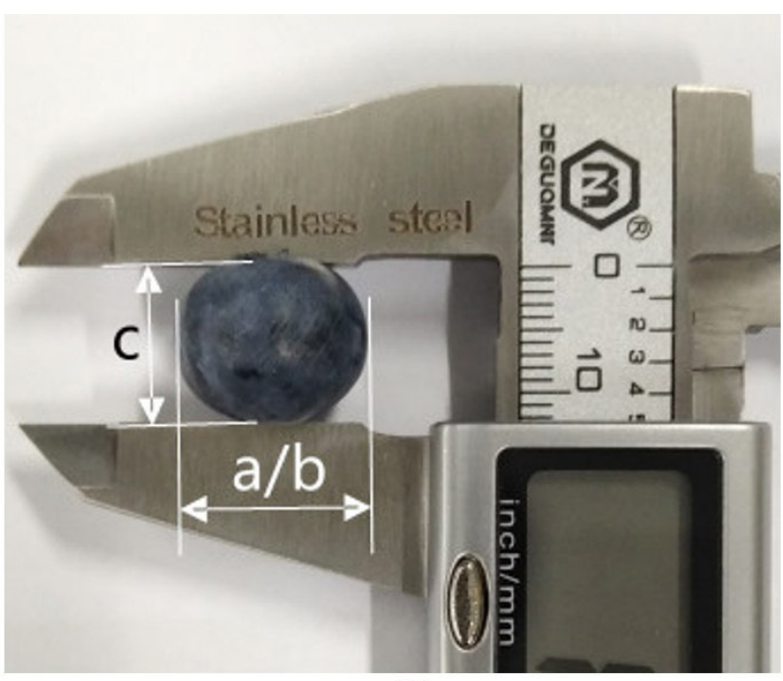

(b)

Figure 1. Experimental devices for OD of blueberries and the measurement of the effective radius of blueberries. (a) thermostatic vibration equipment; (b) measurement of the effective radius for blueberries with an electronic caliper. 
at $20^{\circ} \mathrm{C}$. At temperatures of $10^{\circ} \mathrm{C}$ and $20^{\circ} \mathrm{C}$, xylitol (solubility: $170 \mathrm{~g} / 100 \mathrm{gH}_{2} \mathrm{O}$ ), sorbitol $\left(220 \mathrm{~g} / 100 \mathrm{gH}_{2} \mathrm{O}\right.$ ), maltitol $\left(150 \mathrm{~g} / 100 \mathrm{gH}_{2} \mathrm{O}\right)$, sucrose $\left(204 \mathrm{~g} / 100 \mathrm{gH}_{2} \mathrm{O}\right)$, erythritol $\left(50 \mathrm{~g} / 100 \mathrm{gH}_{2} \mathrm{O}\right)$ and calcium chloride $\left(74.5 \mathrm{~g} / 100 \mathrm{gH}_{2} \mathrm{O}\right)$ were in completely dissolved states in the solutions. The viscosities of the abovementioned polyols, sucrose and calcium chloride $(5 \%$ and $10 \%)$ at $10^{\circ} \mathrm{C}$ and $20^{\circ} \mathrm{C}$ were measured, and the results are listed in Table 1 . As shown in Table 1, the viscosities was decreased with increasing temperature $(\mathrm{p}<0.05)$. At $20^{\circ} \mathrm{C}$, the viscosity of sorbitol was approximately $26.22 \mathrm{mPa} \cdot \mathrm{s}$, which was much higher than those of sucrose (6.17 mPa.s), xylitol(4.18 mPa.s), erythritol (4.78 mPa $\cdot$ ) and maltitol( $4.27 \mathrm{mPa} \cdot \mathrm{s})$, and the viscosity of xylitol in the polyols was the lowest. The molecular weight of xylitol is $152 \mathrm{~g} / \mathrm{mol}$, which is much lower than those of maltitol $(344 \mathrm{~g} / \mathrm{mol})$ and sucrose $(342 \mathrm{~g} / \mathrm{mol})$. A lower molecular weight could increase the osmotic pressure of the ternary solution. The molecular weight of erythritol $(122 \mathrm{~g} / \mathrm{mol})$ is lower than that of xylitol, but the solubility of erythritol is $50 \%$ at $20^{\circ} \mathrm{C}$, which makes it difficult to prepare a higher concentration ternary solution. Therefore, xylitol was selected to prepare ternary solutions, and $40 \% / 5 \%, 40 \% / 10 \%, 50 \% / 5 \%$, and $50 \% / 10 \%$ xylitol $/ \mathrm{CaCl}_{2}$ solutions were prepared. The viscosities of $45 \%, 50 \%, 55 \%$ and $60 \%$ xylitol solutions and the viscosities of the abovementioned ternary solutions were measured, which are also listed in Table 1. The addition of $5 \%$ or $10 \% \mathrm{CaCl}_{2}$ in xylitol solution had little effect on the viscosity in ternary xylitol/ $\mathrm{CaCl}_{2}$ solution $(\mathrm{p}>0.05)$, compared to the viscosity of the $40 \% / 50 \%$ binary xylitol. This could be attributed to the viscosity of the $\mathrm{CaCl}_{2}$ solution at $20^{\circ} \mathrm{C}$ being low (Table 1), and the effects on the viscosities of the ternary solution were not significant. In addition, the viscosities of the ternary solution were affected by the solute-solute and solute- solvent interaction strengths and dissociation or association states. Compared to the viscosities of the $45 \%, 50 \%, 55 \%$ and $60 \%$ binary xylitol solutions, the viscosities of the ternary solutions were lower with the addition of $5 \%$ or $10 \% \mathrm{CaCl}_{2}$ in $40 \%, 50 \%$ xylitol solutions respectively $(\mathrm{p}<0.05) . \mathrm{CaCl}_{2}$ in ternary solution increased the driving force under saturation concentration of xylitol at $20^{\circ} \mathrm{C}$, leading to higher water mass transfer efficiency. According to the experimental results, xylitol/ $\mathrm{CaCl}_{2}$ solution ( $40 \%$ and $50 \%$ xylitol solution adding $5 \%$ or $10 \% \mathrm{CaCl}_{2}$ ) was selected to substitute the sucrose solution for OD of the fresh and frozen blueberries.

\subsection{Water content, xylitol gain and $\mathrm{CaCl} 2$ gain of blueberries in the $O D$ process}

\subsubsection{Water contents of the fresh and frozen blueberries}

The water contents obtained at different times for OD of the fresh and frozen blueberries are shown in Figure-2. Freezing treatment, solution concentration and OD time had significant effects $(\mathrm{p}<0.05)$ on the water content. There were great differences in the OD time used to reach water equilibrium for the fresh and frozen blueberries. After $30 \mathrm{~h}$ OD processing, the fresh blueberries took approximately $22 \mathrm{~h}(\mathrm{p}<0.05)$ to reach equilibrium, whereas frozen blueberries took only $16 \mathrm{~h}$ $(\mathrm{p}<0.05)$, approximately $30 \%$ less time $\left(50 \%\right.$ xylitol $\left./ 10 \% \mathrm{CaCl}_{2}\right)$. Regarding fresh blueberries, the OD equilibrium time decreased by approximately $2 \mathrm{~h}$ with different $\mathrm{CaCl}_{2}$ concentrations (5\% to $10 \%$ ) under the same xylitol concentration conditions. A higher $\mathrm{CaCl}_{2}$ concentration increased the osmotic pressure of the saturated concentration of the solution, resulting in a

Table 1. Concentrations and viscosities of the different solutions.

\begin{tabular}{|c|c|c|c|c|c|c|c|c|c|c|c|}
\hline & \multicolumn{11}{|c|}{ polyols, $\mathrm{CaCl}_{2}$ and Ternary solutions } \\
\hline & \multirow{2}{*}{ Xylitol } & \multirow{2}{*}{ Sobitol } & \multirow{2}{*}{ Erythritol } & \multirow{2}{*}{ Mannitol } & \multirow{2}{*}{ Maltitol } & \multirow{2}{*}{ Sucrose } & \multirow{2}{*}{$\mathrm{CaCl}_{2}$} & \multirow{2}{*}{ Xylitol } & \multirow{2}{*}{ Xylitol } & Xylitol & Xylitol \\
\hline & & & & & & & & & & $/ \mathrm{CaCl}_{2}$ & $/ \mathrm{CaCl}_{2}$ \\
\hline \multirow{3}{*}{$\left({ }^{\circ} \mathrm{C}\right)$} & \multirow{2}{*}{$40 \%$} & \multirow{2}{*}{$40 \%$} & \multirow{2}{*}{$40 \%$} & \multirow{2}{*}{$40 \%$} & \multirow{2}{*}{$40 \%$} & \multirow{2}{*}{$40 \%$} & \multirow{2}{*}{$5 \%$} & \multirow{2}{*}{$45 \%$} & \multirow{2}{*}{$50 \%$} & $40 \% /$ & $40 \% /$ \\
\hline & & & & & & & & & & $5 \%$ & $10 \%$ \\
\hline & \multicolumn{11}{|c|}{ Viscosity $(\mathrm{mPa} \cdot \mathrm{s})$} \\
\hline \multirow{5}{*}{20} & 4.28 & 26.22 & 4.78 & \multirow{2}{*}{$* *$} & 4.27 & 6.17 & 1.11 & 6.54 & 10.51 & 4.52 & 4.63 \\
\hline & \pm 0.31 & \pm 0.20 & \pm 0.33 & & \pm 0.29 & \pm 0.35 & \pm 0.28 & \pm 0.36 & \pm 0.47 & \pm 0.42 & \pm 0.37 \\
\hline & \multicolumn{11}{|c|}{ polyols, $\mathrm{CaCl}_{2}$ and Ternary solutions } \\
\hline & \multirow{2}{*}{ Xylitol } & \multirow{2}{*}{ Sobitol } & \multirow{2}{*}{ Erythritol } & \multirow{2}{*}{ Mannitol } & \multirow{2}{*}{ Maltitol } & $\mathrm{S}_{\text {uroce }}$ & & Y Ylitel & Yolitol & Xylitol & Xylitol \\
\hline & & & & & & sucrose & $\mathrm{CaCl}_{2}$ & xylitol & xylitol & $/ \mathrm{CaCl}_{2}$ & $/ \mathrm{CaCl}_{2}$ \\
\hline & & & & & & $\operatorname{cosity}(\mathrm{mP}$ & & & & & \\
\hline 10 & 13.82 & 60.21 & 14.63 & ** & 16.34 & 25.39 & 1.58 & 17.91 & 28.23 & 13.97 & 14.28 \\
\hline 10 & \pm 0.53 & \pm 0.45 & \pm 0.34 & 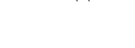 & \pm 0.21 & \pm 0.31 & \pm 0.25 & \pm 0.53 & \pm 0.28 & \pm 0.36 & \pm 0.52 \\
\hline 20 & 10.51 & 54.15 & 10.55 & $* *$ & 13.82 & 15.54 & 1.27 & 14.95 & 20.63 & 10.74 & 11.63 \\
\hline 20 & \pm 0.29 & \pm 0.33 & \pm 0.37 & A & \pm 0.35 & \pm 0.25 & \pm 0.33 & \pm 0.32 & \pm 0.42 & \pm 0.33 & \pm 0.38 \\
\hline
\end{tabular}

T: Temperature; **: Solution crystallization. 
shorter osmotic dehydration equilibrium time and a higher dehydration efficiency (Sacchetti et al., 2001). Regarding frozen blueberries, the water equilibrium time changed by $4 \mathrm{~h}$ with different xylitol concentrations ( $40 \%$ to $50 \%$ ) under the same $\mathrm{CaCl}_{2}$ concentration conditions, which was not statistically significant ( $\mathrm{p}>0.05)$ with different $\mathrm{CaCl}_{2}$ concentrations (5\% to $10 \%)$ under the same xylitol concentration conditions.

The water contents decreased with higher xylitol and $\mathrm{CaCl}_{2}$ concentrations $(\mathrm{p}<0.05)$ in both the fresh and frozen blueberries. Reductions in water content with time were also observed for both fresh and frozen blueberries. Figure 2 shows that the maximum reduction in water content $\left(50 \%\right.$ xylitol $\left./ 10 \% \mathrm{CaCl}_{2}\right)$ decreased by $8 \%$ of the initial water content after $26 \mathrm{~h}$ of OD for fresh blueberries and $12 \%$ of the initial water content for frozen blueberries at the same time (50\% xylitol/ $\left.10 \% \mathrm{CaCl}_{2}\right)$, an approximately $30 \%$ higher efficiency. A comparison of the water contents of the fresh and frozen blueberries showed that the freezing treatment significantly decreased the water contents of blueberries at all the same solution concentrations at less than $26 \mathrm{~h}$ of OD. The rapid reduction in the water content of frozen blueberries could be attributed to outer cuticle and structural changes of blueberries that resulted from the freezing treatment. Freezing treatment caused the fresh blueberries to develop fractures on their surface and in their internal tissues (Ketata et al., 2013).

\subsubsection{Xylitol and $\mathrm{CaCl} 2$ gains of fresh and frozen blueberries}

The results regarding the xylitol and $\mathrm{CaCl}_{2}$ gains of the fresh and frozen blueberries during the OD process in different xylitol/ $/ \mathrm{CaCl}_{2}$ solutions are presented in Figure 3 and Figure 4. There was a greater xylitol gain in the frozen blueberries than in the fresh blueberries at the same concentration $(p<0.05)$. Xylitol gain increased with higher xylitol concentrations $(\mathrm{p}<0.05)$ for

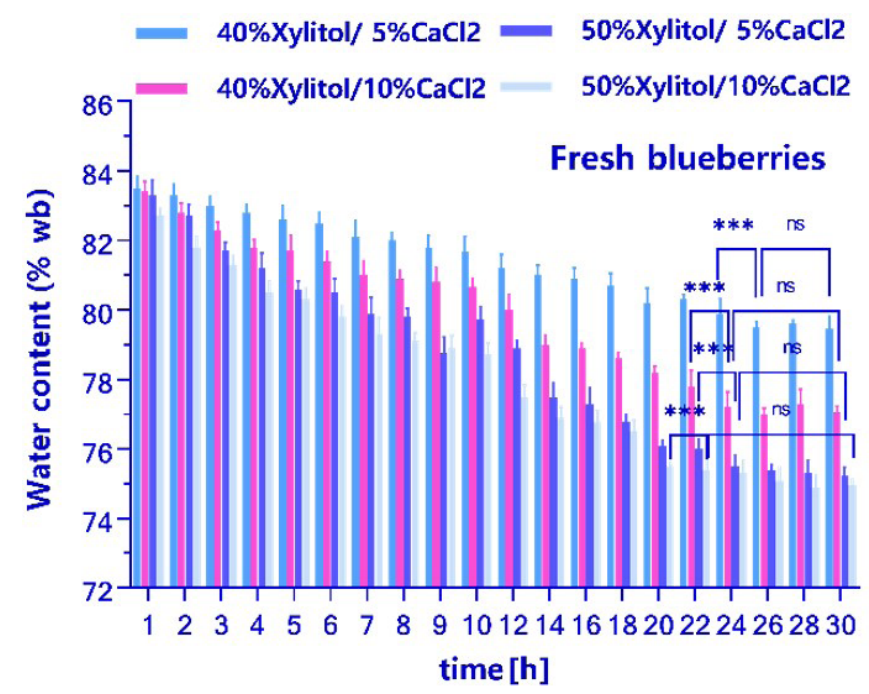

(a) both the fresh and frozen blueberries. As shown in Figure 3a, the greatest xylitol gain was found in the fresh blueberries dehydrated for $26 \mathrm{~h}$ in $50 \%$ xylitol $/ 10 \% \mathrm{CaCl}_{2}$ solution, and the highest xylitol gain was $4.02 \%$. Within $12 \mathrm{~h}$ of OD processing, for $50 \% \mathrm{xylitol} / 10 \% \mathrm{CaCl}_{2}$ the xylitol gain was $2.725 \%$, and for $50 \%$ xylitol $/ 5 \% \mathrm{CaCl}_{2}$, the xylitol gain was $2.95 \%$. For $40 \%$ xylitol/ $10 \% \mathrm{CaCl}_{2}$, the xylitol gain was $2.46 \%$, and for $40 \%$ xylitol $/ 5 \% \mathrm{CaCl}_{2}$, the xylitol gain was $2.62 \%$. Within $12 \mathrm{~h}$ of OD processing, the increase of $5 \% \mathrm{CaCl}_{2}$ solution tended to restrict the xylitol gain for the $40 \%$ and $50 \%$ xylitol solutions. The restriction of calcium on xylitol gain in the fresh blueberries could be attributed to the cell membrane shrinkage caused by higher calcium concentrations restricting the mass transfer of the larger xyliotl molecules $(152 \mathrm{~g} / \mathrm{mol})$. This phenomenon could also be attributed to the interaction between calcium and pectin-methylesterase (PME) (Costa et al., 2011). The presence of the outer epidermal wax on fresh blueberries inhibited the activity of PME (Silva et al., 2014), but the outer epidermal wax was destroyed by the long term OD process. PME could interact with calcium (Haiyan et al., 2014), reinforce the cell walls, and restrict the larger xylitol molecules. However, according to Figure $3 \mathrm{a}$, a longer OD processing time $(12-30 \mathrm{~h})$ provided a higher xylitol gain with higher $\mathrm{CaCl}_{2}$ concentrations. This could be attributed to the fact that longer processing time could damage the skin and tissue of blueberries and increase the xylitol gain in blueberries. As shown in Figure 3b, the freezing treatment tended to increase the xylitol gain. There were no restrictions of calcium on xylitol gain in the frozen blueberries $(p<0.05)$, which could be attributed to the damaging action of the freezing treatment on the outer epidermal wax and the structure of the blueberries. A longer OD processing time could also damage the structure and skin of blueberries and increase the xylitol gain for frozen blueberries.

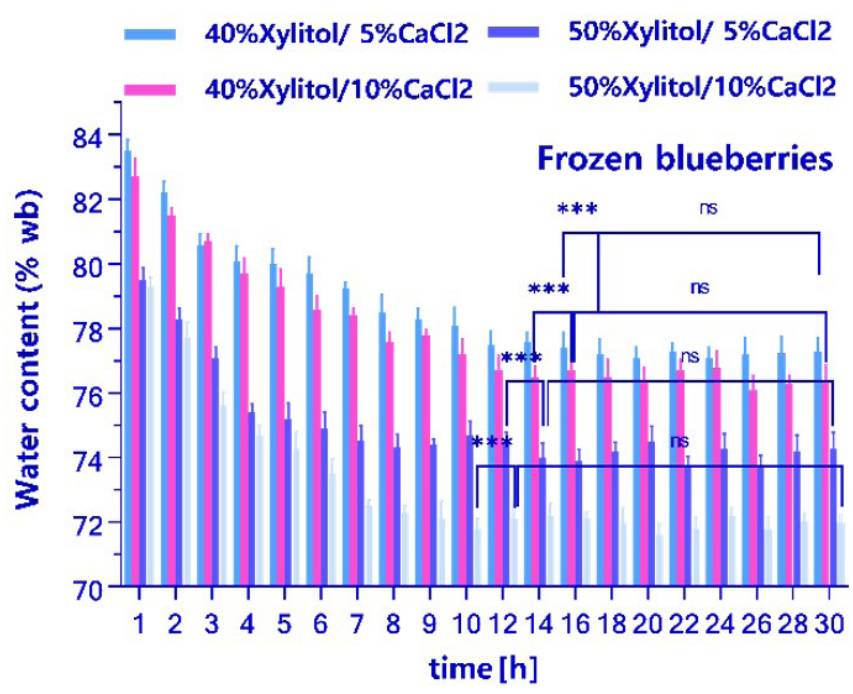

(b)

Figure 2. Water contents (\%) of the fresh and frozen blueberries during OD in different xylitol/CaCl2 solutions at different times. (a) fresh blueberries; (b) frozen blueberries. ( ${ }^{* * *}$ : $\mathrm{p}<0.05$, ns: not significant). 


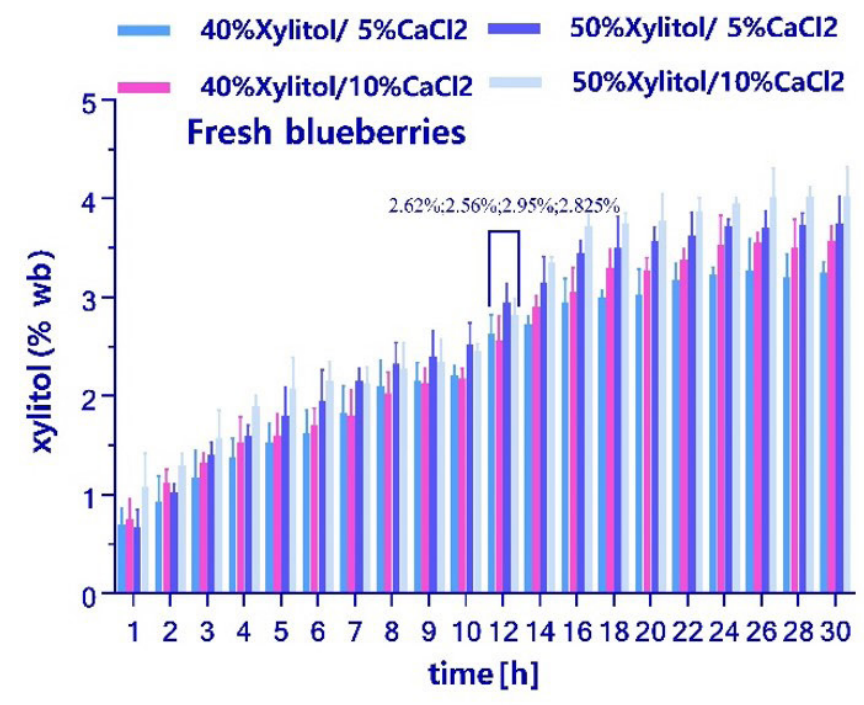

(a)

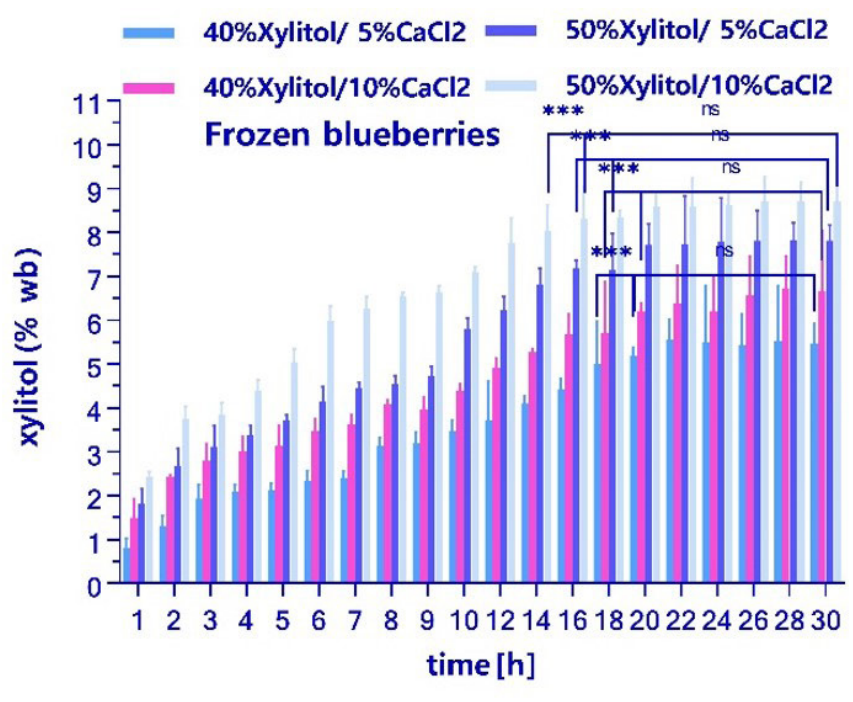

(b)

Figure 3. Xylitol gains (\%, wb) of the fresh and frozen blueberries during $\mathrm{OD}$ in different $\mathrm{xylitol} / \mathrm{CaCl}_{2}$ solutions at different times. (a) fresh blueberries; (b) frozen blueberries. ${ }^{* * *}: \mathrm{p}<0.05$, ns: not significant).

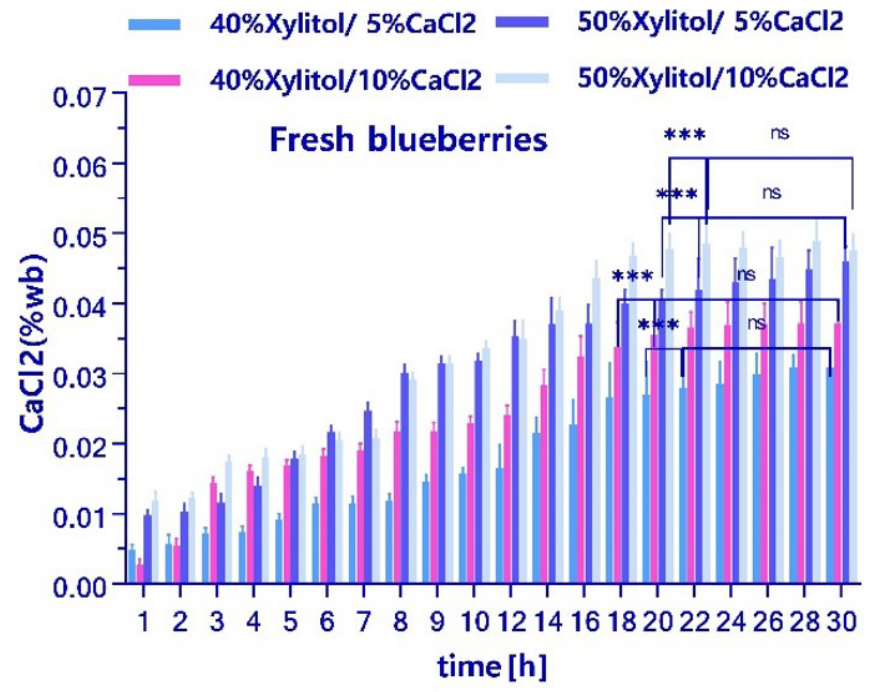

(a)

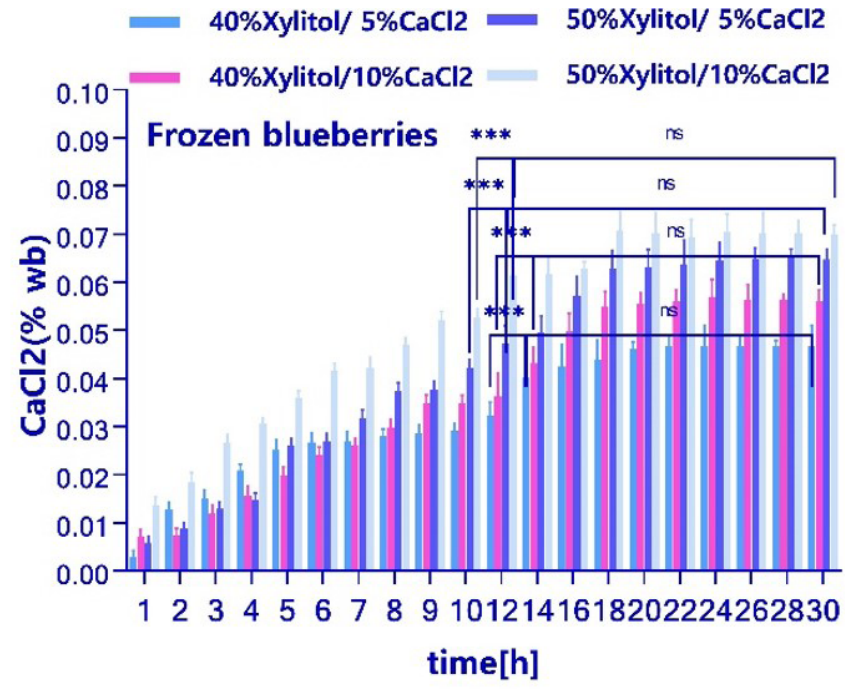

(b)

Figure 4. $\mathrm{CaCl}_{2}$ gains $(\%, w b)$ of fresh and frozen blueberries during $\mathrm{OD}$ in different xylitol/ $\mathrm{CaCl}_{2}$ solutions at different times. (a) fresh blueberries; (b) frozen blueberries. ${ }^{* * *}: \mathrm{p}<0.05$; ns: not significant).

Figure 4 shows the calcium gains of the fresh and frozen blueberries during the OD process in different xylitol/ $\mathrm{CaCl}_{2}$ solutions. There was little difference between the calcium gains of the fresh and frozen blueberries ( $p>0.05)$. The calcium gain increased with increasing xylitol/ $\mathrm{CaCl}_{2}$ solution and processing time. The highest calcium gain was obtained by $18 \mathrm{~h}$ of OD processing in $50 \%$ xylitol/10\% $\mathrm{CaCl}_{2}$ solution for the frozen blueberries and was approximately $0.07 \%$. These results were similar to the calcium gain obtained from the OD of pineapple (Silva et al., 2014), which was OD in $50 \%$ sucrose and $4 \% \mathrm{CaCl}_{2}$ solutions at $27^{\circ} \mathrm{C}$.

\subsection{Effective diffusion coefficients of the fresh and frozen blueberries}

\subsubsection{Determination of the effective diffusion coefficient of the} blueberries in xylitol/CaCl2 solution

After the $30 \mathrm{~h}$ OD process, the volume shrinkage levels were in the ranges of 6-8\% for the fresh blueberries and $10-13 \%$ for the frozen blueberries, as summarized in Table 2. According to Equations 1-3 and the experimental data, effective diffusion coefficients were calculated for water, xylitol and $\mathrm{CaCl}_{2}$ at different 
Table 2. Effective diffusion coefficients of water $\left(D_{\text {water }}, D_{\text {xylitol }}\right.$ and $\left.D_{\mathrm{CaCl} 2}\right)$ for the fresh and frozen blueberries.

\begin{tabular}{|c|c|c|c|c|c|c|c|}
\hline Osmotic & & & & sh blueberr & & & \\
\hline solution & $\begin{array}{c}\text { Volume } \\
\text { shrinkage }\end{array}$ & $\frac{\mathrm{D}_{\text {water }}}{\left(10^{-10} \mathrm{~m}^{2} / \mathrm{s}\right)}$ & $\mathrm{R}^{2}$ & $\frac{\mathrm{D}_{\text {xylitol }}}{\left(10^{-10} \mathrm{~m}^{2} / \mathrm{s}\right)}$ & $\mathrm{R}^{2}$ & $\frac{\mathrm{D}_{\mathrm{CaCl} 2}}{\left(10^{-10} \mathrm{~m}^{2} / \mathrm{s}\right)}$ & $\mathrm{R}^{2}$ \\
\hline $\begin{array}{l}\text { 40\%Xylitol } \\
/ 5 \% \mathrm{CaCl}_{2}\end{array}$ & $6.19 \%$ & 3.945 & 0.948 & 1.386 & 0.934 & 0.206 & 0.980 \\
\hline $\begin{array}{l}\text { 40\%Xylitol } \\
/ 10 \% \mathrm{CaCl}_{2}\end{array}$ & $6.96 \%$ & 4.331 & 0.925 & 1.265 & 0.993 & 0.218 & 0.969 \\
\hline $\begin{array}{l}\text { 50\%Xylitol } \\
/ 5 \% \mathrm{CaCl}_{2}\end{array}$ & $7.53 \%$ & 4.896 & 0.965 & 1.403 & 0.995 & 0.228 & 0.962 \\
\hline $\begin{array}{l}50 \% \text { Xylitol } \\
/ 10 \% \mathrm{CaCl}_{2}\end{array}$ & $7.72 \%$ & 5.007 & 0.978 & 1.538 & 0.988 & 0.663 & 0.982 \\
\hline Osmotic & & & & zen blueber & & & \\
\hline solution & $\begin{array}{c}\text { Volume } \\
\text { shrinkage }\end{array}$ & $\frac{\mathrm{D}_{\text {water }}}{\left(10^{-10} \mathrm{~m}^{2} / \mathrm{s}\right)}$ & $\mathrm{R}^{2}$ & $\frac{\mathrm{D}_{\text {xylitol }}}{\left(10^{-10} \mathrm{~m}^{2} / \mathrm{s}\right)}$ & $\mathrm{R}^{2}$ & $\frac{\mathrm{D}_{\mathrm{CaCl} 2}}{\left(10^{-10} \mathrm{~m}^{2} / \mathrm{s}\right)}$ & $\mathrm{R}^{2}$ \\
\hline $\begin{array}{l}\text { 40\%Xylitol } \\
/ 5 \% \mathrm{CaCl}_{2}\end{array}$ & $10.58 \%$ & 16.58 & 0.976 & 1.733 & 0.984 & 1.238 & 0.971 \\
\hline $\begin{array}{l}\text { 40\%Xylitol } \\
/ 10 \% \mathrm{CaCl}_{2}\end{array}$ & $11.33 \%$ & 24.06 & 0.988 & 2.154 & 0.979 & 1.799 & 0.968 \\
\hline $\begin{array}{l}50 \% \text { Xylitol } \\
/ 5 \% \mathrm{CaCl}_{2}\end{array}$ & $12.30 \%$ & 23.59 & 0.989 & 2.316 & 0.990 & 1.888 & 0.965 \\
\hline $\begin{array}{l}50 \% \text { Xylitol } \\
110 \% \mathrm{CaCl}_{2}\end{array}$ & $12.66 \%$ & 25.63 & 0.993 & 2.412 & 0.989 & 1.778 & 0.926 \\
\hline
\end{tabular}

concentrations considering volume shrinkage (Table 2). Table 2 also includes the values of the determination coefficient $R^{2}$. According to the analysis results, the majority of the $R^{2}$ values were higher than 0.9 .

The effective diffusion coefficients of water $\left(D_{\text {water }}\right)$ were in the ranges of $3.945 \times 10^{-10}$ to $5.007 \times 10^{-10} \mathrm{~m}^{2} / \mathrm{s}$ for the fresh blueberries and $16.58 \times 10^{-10}$ to $25.63 \times 10^{-10} \mathrm{~m}^{2} / \mathrm{s}$ for the frozen blueberries under different concentrations considering volume shrinkage. These results for fresh blueberries were smaller than the diffusion coefficient data $\left(5.104 \times 10^{-10} \mathrm{~m}^{2} / \mathrm{s}\right)$ obtained for fresh blueberries from other researchers (Nsonzi \& Ramaswamy, 1998), who performed OD in 60 Brix sucrose solutions $\left(60^{\circ} \mathrm{C}\right)$. This kind of difference could be attributed to the OD temperature difference. A higher temperature was attributed to a higher mass transfer efficiency and a larger effective diffusion coefficient. Moreover, the diffusion coefficients reported in other studies did not consider the volume shrinkage. In related research, effective diffusion coefficients considering the volume shrinkage of the OD product were smaller than those without considering volume shrinkage (Zecchi \& Gerla, 2019). Regarding the frozen blueberries, $D_{\text {water }}$ greatly increased with the freezing treatment, which could be related to the destruction of the blueberries' epicuticular wax by the freezing treatment at all solution concentrations. Similar increases could also be found in the results of $D_{\text {xylitol }}$ and $D_{\mathrm{CaCl} 2}$.

\subsubsection{Effects of solution concentration and vibration speed on the effective diffusion coefficients of blueberries}

The effects of solution concentration and vibration speed on the effective diffusion coefficients of the blueberries were determined. The results including significant regression, no
Table 3. Coded second-order regression coefficients for $D_{\text {water }}, D_{\text {xylitol }}$ and $D_{\mathrm{CaCl} 2}$ of fresh and frozen blueberries.

\begin{tabular}{ccccc}
\hline \multirow{2}{*}{ Coefficients } & \multicolumn{2}{c}{ Fresh blueberries } & \multicolumn{2}{c}{ Frozen blueberries } \\
\cline { 2 - 5 } & $\mathrm{D}_{\text {water }}$ & $\mathrm{D}_{\text {xylitol }}$ & $\mathrm{D}_{\text {water }}$ & $\mathrm{D}_{\text {xylitol }}$ \\
\hline$\beta_{0}$ & 4.02 & 1.37 & 22.28 & 2.53 \\
$\beta_{1}$ & 0.20 & 0.14 & 0.91 & 0.068 \\
$\beta_{2}$ & 0.4 & 0.13 & 1.25 & 0.089 \\
$\beta_{3}$ & 0.82 & 0.56 & 3.61 & 0.37 \\
$\beta_{11}$ & $\mathrm{Ns}$ & $\mathrm{Ns}$ & -1.22 & -0.1 \\
$\beta_{22}$ & $\mathrm{Ns}$ & $\mathrm{Ns}$ & $\mathrm{Ns}$ & $\mathrm{Ns}$ \\
$\beta_{33}$ & $\mathrm{Ns}$ & 0.12 & -1.53 & 0.072 \\
$\beta_{12}$ & $\mathrm{Ns}$ & $\mathrm{Ns}$ & $\mathrm{Ns}$ & $\mathrm{Ns}$ \\
$\beta_{13}$ & -0.20 & 0.081 & $\mathrm{Ns}$ & $\mathrm{Ns}$ \\
$\beta_{23}$ & $\mathrm{Ns}$ & 0.072 & $\mathrm{Ns}$ & $\mathrm{Ns}$ \\
$R^{2}$ & 0.9646 & 0.9781 & 0.9538 & 0.9741 \\
$F$ & 49.40 & 80.23 & 16.05 & 29.20 \\
$p$-Value & $<0.0001$ & $<0.005$ & $<0.0007$ & $<0.0001$
\end{tabular}

Ns: Not significant.

lack of fit and satisfactory $R^{2}$ values are presented in Table 3. The model was not significant for $D_{\mathrm{CaCl} 2}$ for either the fresh or frozen blueberries. According to Table 3, both xylitol and $\mathrm{CaCl}_{2}$ concentrations showed significant effects $(\mathrm{p}<0.05)$ on $D_{\text {water }}$ and $D_{\text {xylitol }}$, for the fresh and frozen blueberries. Vibration speed showed the largest significant effects $(\mathrm{p}<0.05)$ on $D_{\text {water }}$ and $D_{\text {xylitol }}$ in the fresh and frozen blueberries. Neither of the interactive variables showed a significant effect on the $D_{\text {water }}$ and $D_{\text {xylitol }}$ of the frozen blueberries.

Regarding $D_{\text {water }}$ of the fresh blueberries, calcium ions can cause structural changes in the membranes of fruit, leading to an increase in their permeability (Junqueira et al., 2017). Moreover, 
the $\mathrm{CaCl}_{2}$ in the ternary solution increased the driving force under a saturation concentration of xylitol at $20^{\circ} \mathrm{C}$, leading to a higher water mass transfer efficiency. A higher vibration speed further decreased the external resistance of the ternary solution on the blueberry-solution surface.

The $D_{\text {xylitol }}$ of the fresh blueberries was also affected by the solute concentration. The increase in $\mathrm{CaCl}_{2}$ concentration led to an increase in the $D_{\text {xylitol }}$ at the initial time, and further addition of $\mathrm{CaCl}_{2}$ showed a marginally positive effect on the $D_{\text {xylitol }}$. This effect could also be explained by the formation of a solid barrier at the fruit surface (Silva et al., 2014; Haiyan et al., 2014), which could make the xylitol transfer more difficult at higher $\mathrm{CaCl}_{2}$ concentrations. The $D_{\text {xylitol }}$ of the fresh blueberries increased greatly with increasing vibration speed.

The $D_{\text {water }}$ of frozen blueberries increased with increasing $\mathrm{CaCl}_{2}$ and xylitol concentrations. This increase could be attributed to some structural changes in blueberries that occur due to the freezing treatment, which increased the permeability of the water and xylitol transfers. The $D_{\text {water }}$ increased significantly with increasing vibration speed. The vibration speed had a more significant effect on the $D_{\text {water }}$ of the frozen blueberries than on that of the fresh blueberries. The $D_{\text {xylitol }}$ of the frozen blueberries increased greatly with increasing vibration speed, which was similar to the effect of vibration speed on the fresh blueberries. At $20^{\circ} \mathrm{C}$, the mass transfer between the blueberries and xylitol/ $/ \mathrm{CaCl}_{2}$ solution was probably governed by the external resistance of the solution viscosity and the blueberry skins. Vibration and freezing treatment could improve the efficiency of OD in $\mathrm{xylitol} / \mathrm{CaCl}_{2}$ solution at low temperature.

\section{Conclusions}

Xylitol and $\mathrm{CaCl}_{2}$ were valuable components of the novel ternary solution considering low-viscosity, low-sugar and low-salt requirements. At the same vibration speed $(600 \mathrm{rpm})$, the mass transfer of fresh and frozen blueberries was affected by the diffusion mechanism of the ternary solution at $20^{\circ} \mathrm{C}$. The frozen blueberries had an increased OD efficiency compared with the fresh blueberries in different $\mathrm{xylitol} / \mathrm{CaCl}_{2}$ solutions. There was competition between xylitol and $\mathrm{CaCl}_{2}$ transfer at a shorter OD time $(12 \mathrm{~h})$ for fresh blueberries, which was not significant in OD of the frozen blueberries at longer OD processing times $(12 \mathrm{~h}-30 \mathrm{~h})$. Considering volume shrinkage and low temperature, the effective diffusion coefficient of water was smaller than the those reported by other researchers for fresh blueberries. The vibration speed was the most important factor influencing the effective diffusion coefficient, which governed the mass transfer efficiency of the fresh and frozen blueberries in the ternary solution.

\section{Acknowledgement}

The authors acknowledge the support provided by the National Natural Science Foundation of China (51476049) and the support provided by the Project of Harbin Science and Technology Bureau (Project No.2016RAQXJ023).

\section{Reference}

Akharume, F., Singh, K., \& Sivanandan, L. (2016). Characteristics of apple juice and sugar infused fresh and frozen blueberries. Lebensmittel-Wissenschaft + Technologie, 73, 448-457. http://dx.doi. org/10.1016/j.lwt.2016.06.041.

Allan-Wojtas, P. M., Forney, C. F., Carbyn, S. E., \& Nicholas, K. (2001). Microstructural indicators of quality-related characteristics of blueberries-An integrated approach. Lebensmittel-Wissenschaft + Technologie, 34(1), 23-32. http://dx.doi.org/10.1006/fstl.2000.0738.

Chen, A. M., Yang, J. J., Yang, X. R., Liang, J. H., \& Zhu, J. L. (2013). Determination of xylitol and the lower polyols derived from xylitol hydrogenolysis by hplc method. Modern Chemical Industry, 33, 131-133.

Cichowska, J., Żubernik, J., Czyżewski, J., Kowalska, H., \& WitrowaRajchert, D. (2018). Efficiency of osmotic dehydration of apples in polyols solutions. Molecules (Basel, Switzerland), 23(2), 446. http:// dx.doi.org/10.3390/molecules23020446. PMid:29462977.

Ciurzyńska, A., Kowalska, H., Czajkowska, K., \& Lenart, A. (2016). Osmotic dehydration in production of sustainable and healthy food. Trends in Food Science \& Technology, 50, 186-192. http://dx.doi. org/10.1016/j.tifs.2016.01.017.

Costa, A. S., Silva, C., Costa, L., Barros, N., Viana, E., Koblitz, M., et al (2011 July 13-15). Use of response surface methodology for optimization of the extraction of enzymes from pineapple pulp. VII International Pineapple Symposium (pp. 575-584), Johor, Malaysia.

Dermesonlouoglou, E., \& Giannakourou, M. C. (2018). Modelling dehydration of apricot in a non-conventional multi-component osmotic solution: effect on mass transfer kinetics and quality characteristics. Journal of Food Science and Technology, 55(10), 4079-4089. http:// dx.doi.org/10.1007/s13197-018-3334-4. PMid:30228406.

Derossi, A., Severini, C., Del Mastro, A., \& De Pilli, T. (2015). Study and optimization of osmotic dehydration of cherry tomatoes in complex solution by response surface methodology and desirability approach. Lebensmittel-Wissenschaft + Technologie, 60(2), 641-648. http://dx.doi.org/10.1016/j.lwt.2014.10.056.

Dimakopoulou-Papazoglou, D., \& Katsanidis, E. (2016). Mass transfer kinetics during osmotic processing of beef meat using ternary solutions. Food and Bioproducts Processing, 100, 560-569. http:// dx.doi.org/10.1016/j.fbp.2016.09.001.

Dimakopoulou-Papazoglou, D., \& Katsanidis, E. (2019). Diffusion coefficients and volume changes of beef meat during osmotic dehydration in binary and ternary solutions. Food and Bioproducts Processing, 116, 10-19. http://dx.doi.org/10.1016/j.fbp.2019.04.007.

Grajales-Lagunes, A., Cabrera-Ruiz, L., Gutirrez-Miceli, F., RuizCabrera, M. A., \& Abud-Archila, M. (2019). Anthocyanins from blackberry (rubus fructicosus 1.) impregnated in yam bean (pachyrhizus erosus (1.) urb.) by osmotic dehydration. Food Science and Technology (Campinas), 39(4), 922-929. http://dx.doi. org/10.1590/fst.15618.

Haiyan, G., Shuai, Y., Hangjun, C., Wenjing, C., Honglei, M., \& Linmei, G. (2014). Epicuticular wax's effect on fruit softening of blueberry. Journal of Chinese Institute of Food Science and Technology, 14, 102-108.

Junqueira, J. R. J., Corréa, J. L. G., \& Mendona, K. S. (2017). Evaluation of the shrinkage effect on the modeling kinetics of osmotic dehydration of sweet potato (ipomoea batatas (1.)). Journal of Food Processing and Preservation, 41(3), 1745-4549. http://dx.doi. org/10.1111/jfpp.12881.

Junqueira, J. R. J., Corréa, J. L. G., Mendona, K. S., Junior, R., \& Souza, A. U. (2021). Modeling mass transfer during osmotic dehydration of different vegetable structures under vacuum conditions. Food 
Science and Technology (Campinas), 41(2), 439-448. http://dx.doi. org/10.1590/fst.02420.

Ketata, M., Desjardins, Y., \& Ratti, C. (2013). Effect of liquid nitrogen pretreatments on osmotic dehydration of blueberries. Journal of Food Engineering, 116(1), 202-212. http://dx.doi.org/10.1016/j. jfoodeng.2012.10.035.

Kowalska, H., Marzec, A., Kowalska, J., Ciurzyńska, A., Czajkowska, K., Cichowska, J., Rybak, K., \& Lenart, A. (2017). Osmotic dehydration of honeoye strawberries in solutions enriched with natural bioactive molecules. Lebensmittel-Wissenschaft + Technologie, 85, 500-505. http://dx.doi.org/10.1016/j.lwt.2017.03.044.

Kucner, A., Klewicki, R., \& Sójka, M. (2013). The influence of selected osmotic dehydration and pretreatment parameters on dry matter and polyphenol content in highbush blueberry(vaccinium corymbosum L.)fruits. Food and Bioprocess Technology, 6(8), 2031-2047. http:// dx.doi.org/10.1007/s11947-012-0997-0.

Monnerat, S. M., Pizzi, T., Mauro, M. A., \& Menegalli, F. C. (2010). Osmotic dehydration of apples in sugar/salt solutions: concentration profiles and effective diffusion coefficients. Journal of Food Engineering, 99(4), 604-612. http://dx.doi.org/10.1016/j.jfoodeng.2010.05.008.

Nsonzi, F., \& Ramaswamy, H. S. (1998). Osmotic dehydration kinetics of blueberries. Drying Technology, 16(3-5), 725-741. http://dx.doi. org/10.1080/07373939808917432.

Omobuwajo, T. O., Akande, E. A., \& Sanni, L. A. (1999). Selected physical, mechanical and aerodynamic properties of african breadfruit (treculia africana) seeds. Journal of Food Engineering, 40(4), 241-244. http:// dx.doi.org/10.1016/S0260-8774(99)00060-6.

Jesus Junqueira, J. R., Corrêa, J. L. G., de Mendonça, K. S., Resende, N. S., \& de Barros Vilas Boas, E. V. (2017). Influence of sodium replacement and vacuum pulse on the osmotic dehydration of eggplant slices. Innovative Food Science \& Emerging Technologies, 41, 10-18. http://dx.doi.org/10.1016/j.ifset.2017.01.006.

Rodrigues, D. M., Souza, V. D., Mendes, J. F., Nunes, C. A., \& Pinheiro, A. (2016). Microparticulated salts mix: an alternative to reducing sodium in shoestring potatoes. Lebensmittel-Wissenschaft + Technologie, 69, 390-399. http://dx.doi.org/10.1016/j.lwt.2016.01.056.

Sacchetti, G., Gianotti, A., \& Rosa, M. D. (2001). Sucrose-salt combined effects on mass transfer kinetics and product acceptability. study on apple osmotic treatments. Journal of Food Engineering, 49(2/3), 163-173. http://dx.doi.org/10.1016/S0260-8774(00)00206-5.

Shi, M., Loftus, H., Mcainch, A. J., \& Su, X. Q. (2017). Blueberry as a source of bioactive compounds for the treatment of obesity, type
2 diabetes and chronic inflammation. Journal of Functional Foods, 30, 16-29. http://dx.doi.org/10.1016/j.jff.2016.12.036.

Silva, K. S., Fernandes, M. A., \& Mauro, M. A. (2014). Effect of calcium on the osmotic dehydration kinetics and quality of pineapple. Journal of Food Engineering, 134(134), 37-44. http://dx.doi.org/10.1016/j. jfoodeng.2014.02.020.

Song, C., Ma, X., Li, Z., Wu, T., Raghavan, G. V., \& Chen, H. (2020). Mass transfer during osmotic dehydration and its effect on anthocyanin retention of microwave vacuum-dried blackberries. Journal of the Science of Food and Agriculture, 100(1), 102-109. http://dx.doi. org/10.1002/jsfa.9999. PMid:31436308.

Telis, V., Murari, R., \& Yamashita, F. (2004). Diffusion coefficients during osmotic dehydration of tomatoes in ternary solutions. Journal of Food Engineering, 61(2), 253-259. http://dx.doi.org/10.1016/ S0260-8774(03)00097-9.

Tonon, R. V., Baroni, A. F., \& Hubinger, M. D. (2007). Osmotic dehydration of tomato in ternary solutions: influence of process variables on mass transfer kinetics and an evaluation of the retention of carotenoids. Journal of Food Engineering, 82(4), 509-517. http:// dx.doi.org/10.1016/j.jfoodeng.2007.03.008.

Vega-Gálvez, A., Lara, E., Flores, V., Scala, K. D., \& Lemus-Mondaca, R. (2012). Effect of selected pretreatments on convective drying process of blueberries (var. o'neil). Food and Bioprocess Technology, 5(7), 1-8. http://dx.doi.org/10.1007/s11947-011-0656-x.

Yadav, A. K., \& Singh, S. V. (2014). Osmotic dehydration of fruits and vegetables: a review. Journal of Food Science and Technology, 51(9), 1654-1673. http://dx.doi.org/10.1007/s13197-012-0659-2. PMid:25190823.

Yu, Y., Jin, T. Z., Fan, X., \& Xu, Y. (2016). Osmotic dehydration of blueberries pretreated with pulsed electric fields: effects on dehydration kinetics, and microbiological and nutritional qualities. Drying Technology, 35(13), 1543-1551. http://dx.doi.org/10.1080/0 7373937.2016.1260583.

Yu, Y., Jin, T. Z., Fan, X., \& Wu, J. (2017). Biochemical degradation and physical migration of polyphenolic compounds in osmotic dehydrated blueberries with pulsed electric field and thermal pretreatments. Food Chemistry, 239, 1219-1225. http://dx.doi. org/10.1016/j.foodchem.2017.07.071. PMid:28873543.

Zecchi, B., \& Gerla, P. (2019). Effective diffusion coefficients and mass flux ratio during osmotic dehydration considering real shape and shrinkage. Journal of Food Engineering, 274, 109-132. 